\title{
Nitrogen-Doped Porous Carbon Nanofiber Supported Platinum as Promising Oxygen Reduction Reaction Electrocatalysts
}

\author{
Yi Ding, Kang Fu, Yang Wang, Shenglin Yang, Junhong Jin, Guang Li* \\ State Key Laboratory for Modification of Chemical Fibers and Polymer Materials, College of Materials Science and Engineering, \\ Donghua University, Shanghai, China \\ Email: lig@dhu.edu.cn
}

How to cite this paper: Ding, Y., Fu, K., Wang, Y., Yang, S.L., Jin, J.H. and Li, G. (2017) Nitrogen-Doped Porous Carbon Nanofiber Supported Platinum as Promising Oxygen Reduction Reaction Electrocatalysts. Journal of Materials Science and Chemical Engineering, 5, 1-9.

https://doi.org/10.4236/msce.2017.57001

Received: April 12, 2017

Accepted: July 4, 2017

Published: July 7, 2017

\begin{abstract}
Heteroatoms doped Carbon materials have been proved as promising catalyst support material for oxygen reduction reaction (ORR) in proton exchange membrane fuel cell (PEMFC). In this paper, nitrogen-doped porous nanofibers (N-PCNF) were fabricated via cost effective electrospinning technique by blending the PI and PAN as precursors, followed by heat treatment procedures. The N-PCNFs were used as support to prepare platinum $(\mathrm{Pt})$ catalyst (Pt/N-PCNFs). SEM figure indicated that the porous structures not only existed on the surface but also in the cross session of the fibers. XPS and TEM displayed that with the help of heteroatoms nitrogen, the fiber had rougher surface and more defective structure, contributing to the dispersion of Pt nanoparticles. The catalytic performance for ORR was evaluated by cyclic voltammetry (CV) and liner sweep voltammetry (LSV) with a rotating disk electrode (RDE). According to the results, $\mathrm{Pt} / \mathrm{N}-\mathrm{PCNF}$ exhibited superior property (more positive onset potential and half-wave potential) than that of JM20. The excellent ORR activity of Pt/N-PCNF was attributed to the enriched nitrogen heteroatoms coordinated within the microstructure which increased the exposure of more active sites and dispersion of Pt nanoparticles.
\end{abstract}

\section{Keywords}

N-Doped Porous Carbon Nanofiber(N-PCNF), Electrospinning, Oxygen Reduction Reaction(ORR)

\section{Introduction}

As a clean, efficient and sustainable new energy system, fuel cell has become one of the effective ways to solve the global energy crisis and environmental pollu- 
tion problem [1]. However, the large-scale commercial applications of fuel cells have still been hampered by some technical problems [2] (such as high cost, methanol crossover effect and poor durability). So far Pt loaded on carbonaceous supports have been considered as one of the most applicable ORR electro-catalysts. However, the regular carbon supports are susceptible to carbon corrosion (oxidation), resulting in a significant reduction in catalytic performance, particularly at high potential conditions. In this situation, an effective alternative to low-cost, high-performance corrosion-resistant catalyst supports are vital for the application of PEMFC.

Currently, carbon materials doped with various heteroatoms have been confirmed as a promising alternative support material in ORR. A large quantity of report has proved that the heteroatoms (including $\mathrm{N}, \mathrm{S}, \mathrm{Fe}$, and $\mathrm{Co}$ ) have a positive effect for ORR activity. Several Nitrogen-doped material such as $\mathrm{N}$-doped carbon nano-graphene (NG) [3] [4], and N-doped Carbon Nanohorn [5] have been prepared successfully and exhibited preeminent characteristic for ORR.

Among them nitrogen-doped carbon nanofiber (N-PCNF) has received widespread attention. Carbon nanofibers with high conducting property which can provide efficient pathways for electrons are regarded as a promising support material. Furthermore the pyridinic N in N-PCNF can increase the defect of the fiber, thus enhance the active sites for ORR [6] [7]. Lui [8] has prepared a kind of N-CNF through urea treatment. The obtained N-CNF exhibited better catalytic activity than the traditional carbon nanofibers. The study demonstrated the effectiveness of nitrogen doped nanofiber.

In this paper, we developed a series of nitrogen doped porous carbon nanofibers via using Polyimide (PI) as nitrogen precursor with different content. Then $\mathrm{N}$-PCNFs were used as support materials to deposited Pt nanoparticles. The electrocatalytic performance for ORR and the role of nitrogen were tested and discussed.

\section{Experiment}

\subsection{Preparation of PI}

The soluble PI was synthesized via the copolymerization of 2,2'-Bis (trifluoromethyl) benzidine (TFMB) , 2-(4-Aminophenyl-1H-benzimidazol-5-mine (BIA) and 3,3',4,4'-Benzophenonetetracarboxylic dianhydride (BTDA). Briefly, a calculated amount of TFMB, BIA and equimolar BTDA were dispersed in 1-Methyl-2-pyrrolidinone (NMP) in a three-necked flask, with a solid content of $15 \mathrm{wt} \%$. The mixture was stirred at room temperature for $8 \mathrm{~h}$ to form a highly viscous poly(amic acid) solution. Whereafter, the poly(amic acid) was converted to polyimide by thermal imidization process at $195^{\circ} \mathrm{C}$ for $10 \mathrm{~h}$. Finally the PI film was obtained through tape casting at $70^{\circ} \mathrm{C}$ in vacuum oven for $24 \mathrm{~h}$.

\subsection{Preparation of Nitrogen Doped Porous Nanofibers (N-PCNF)}

The N-PCNF was synthesized by electrospinning technique. For spinning solution, $70 \mathrm{wt} \%$ polyacrylonitrile (PAN), $30 \mathrm{wt} \%$ polymethylmethacrylate (PMMA), 
polyimide (PI) and N, N-dimethylacetamide (DMAc) were used as polymer, Pore former, N-contenting precursor and dispersant solvent, respectively. Then the mixed solution was stirring for $12 \mathrm{~h}$ at $40^{\circ} \mathrm{C}$ to disperse uniformly. The precursor solution was loaded in a syringe with a diameter of $0.4 \mathrm{~mm}$ spinneret and fed at a speed of $15 \mu \mathrm{l} / \mathrm{min}$. The electrospinning voltage is $18 \mathrm{kV}$ and the distance between the needle and collector is $18 \mathrm{~cm}$. Then the fibrous films were dried under vacuum for $12 \mathrm{~h}$ to evaporate the residual solvent. The pre- oxidation was treated under $280^{\circ} \mathrm{C}$ for $1 \mathrm{~h}$ followed by carbonization at $900^{\circ} \mathrm{C}$ under the N2 flow. The sample were denoted based on the content of PI (0 wt\%, 30 wt\%, 50 wt\%, 100 wt\%) as PCNF, N-PCNF (PI-30\%), N-PCNF (PI-50\%), N-PCNF (PI-100\%).

The surface structure and morphology of the nanofiber catalysts were investigated via scanning electron microscopy (SEM), transmission electron microscopy (TEM) and X-ray photoelectron spectroscopy (XPS).

\subsection{Synthesis of N-PCNF Loaded Platinum Nanoparticles (Pt/N-PCNF)}

The loading of Pt was processed via traditional ethylene glycol (EG) technique [9]. Briefly, 40mg as prepared N-PCNF and 30ml EG were added into flask and went through ultrasonic treatment for $1 \mathrm{~h}$ to afford a homogeneous ink. A certain amount of $\mathrm{H}_{2} \mathrm{PtCl}_{6} \cdot 6 \mathrm{H}_{2} \mathrm{O}$ aqueous solution $(7.53 \mathrm{mg} / \mathrm{mL}$ of $\mathrm{Pt}$ ) was subsequently added to the ink and followed by ultrasonic treatment for another $1 \mathrm{~h}$. Then the ink was heated at $140^{\circ} \mathrm{C}$ with stir for $4 \mathrm{~h}$ under $\mathrm{N}_{2}$ atmosphere. After cooling down, the ink of $\mathrm{Pt} / \mathrm{N}-\mathrm{PCNF}$ was separated in the centrifuge and washed by deionized water and acetone for several times. Finally, the catalysts were dried in the vacuum at $70^{\circ} \mathrm{C}$ for $12 \mathrm{~h}$.

\subsection{Electrochemical Measurements}

The electrochemical properties were performed in a standard three-electrode system controlled by $\mathrm{CHI} 760 \mathrm{E}$ electrochemical station. A saturated calomel and platinum electrode were used as the reference electrode and the counter electrode, respectively. For working electrode, $4 \mathrm{mg} \mathrm{Pt} / \mathrm{N}-\mathrm{PCNF}$ catalysts were dispersed in $2 \mathrm{ml}$ methanol/Nafion (5 $\mathrm{wt} \%$ ) solvent and ultrasonicated for $1 \mathrm{~h}$ to form a homogeneous suspension. Then catalyst ink was pipetted onto the working ring disk electrode $\left(0.2475 \mathrm{~cm}^{2}\right)$ and dried under ambient conditions. The loading of the catalyst was about $16.6 \mathrm{mg} / \mathrm{cm}^{2}$. The liquid electrolyte was $0.1 \mathrm{M}$ $\mathrm{HClO}_{4}$ aqueous solvent and bubbled with $\mathrm{N}_{2}$ and $\mathrm{O}_{2}$ about 30 minutes for cyclic voltammetry (CV) and linear sweep voltammetry (LSV) test. CV test was carried out at a scan rate of $50 \mathrm{~m} \cdot \mathrm{Vs}^{-1}$. LSV was test at a scan rate of $5 \mathrm{~m} \cdot \mathrm{Vs}^{-1}$ and rotating speed of $1600 \mathrm{rpm}$.

\section{Results and Discussion}

In this study, we fabricated the N-PCNF through electrospinning and subsequent calcination. The morphologies of the nanofibers were observed by SEM. 
As shown in Figures 1(a)-(f), the average diameter of fiber was approximately on the range of $150 \mathrm{~nm}-300 \mathrm{~nm}$. All fibers showed porous structure. But obviously, N-PCNF (PI-30\%) possessed more pores and rougher surface. Meanwhile, porous structure of N-PCNF (PI-30\%) not only presented on the surface, but also in the internal of the fiber (Figure 1(c)). Thus, both cross-section and surface of PCNFs became more defective and rougher which might benefit the distribution and deposition of $\mathrm{Pt}$ nanoparticles.

To investigate the chemical structure of N-PCNFs, X-ray photoelectron spectroscopic (XPS) measurements were tested. All samples showed peaks corresponding to C1s, O1s, and N1s (Figure 2). Furthermore, high-resolution XPS N 1s spectra were curve fitted to reveal the chemical states of the nitrogen dopants. Three different type of nitrogen configurations located at around 398, 399.6, and $401.2 \mathrm{eV}$ were found, corresponding to pyridinic $\mathrm{N}$, pyrrolic $\mathrm{N}$, and graphitic $\mathrm{N}$ [10], respectively (Figures 3(a)-(d) and Table 1). Obviously, overall N content of PCNF and N-PCNF (PI-100\%) were lower than the blending fibers. The data indicated that the blending process could increase the overall $\mathrm{N}$ content and the best blending ratio was $30 \mathrm{wt} \%$. Also, N-PCNF (PI-30\%) (43.89\%) showed the higher proportion of pyridinic nitrogen compared with the other samples (PCNF, 19.53\%, N-PCNF (PI-50\%), 40\%, N-PCNF (PI-100\%), 29\%). The curves suggested that with the blending of PI the nitrogen structure tended to transfer to pyridinic nitrogen during the pyrolysis process and it has been extensively reported that the pyridinic nitrogen would boost the ORR activity, while the pyrrolic nitrogen and graphitic nitrogen have little effect [11].

The characterization of Pt nanoparticles supported on fibers was examined by TEM. The Pt loadings were in the same content with mass ratio of $20 \mathrm{wt} \%$. As shown in Figures 4(a)-(d), Pt nanoparticles were uniformly deposited on all PCNFs in spite that there still existed a certain degree of aggregation on the surface and edge of N-PCNF. The average size of Pt nanoparticles was approximately ranged from 2 to $4 \mathrm{~nm}$. Compare with other samples, N-PCNF (PI-30\%)
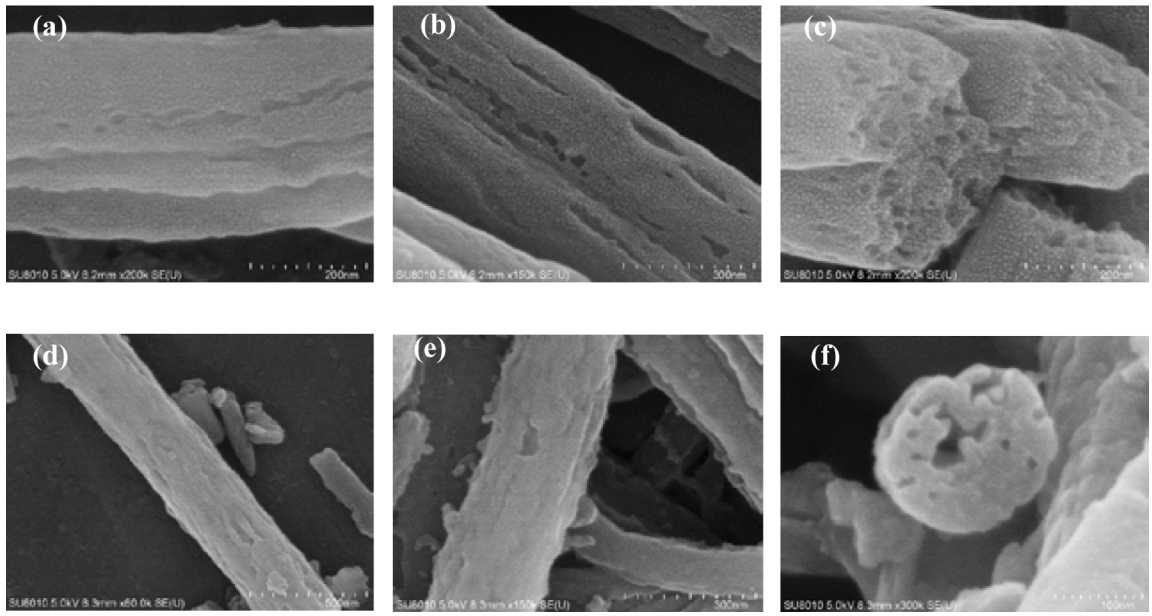

Figure 1. SEM images of PCNF (a), N-PCNF (PI-30\%) (b) (c), N-PCNF(PI-50\%) (d) and N-PCNF(PI-100\%) (e) (f). 


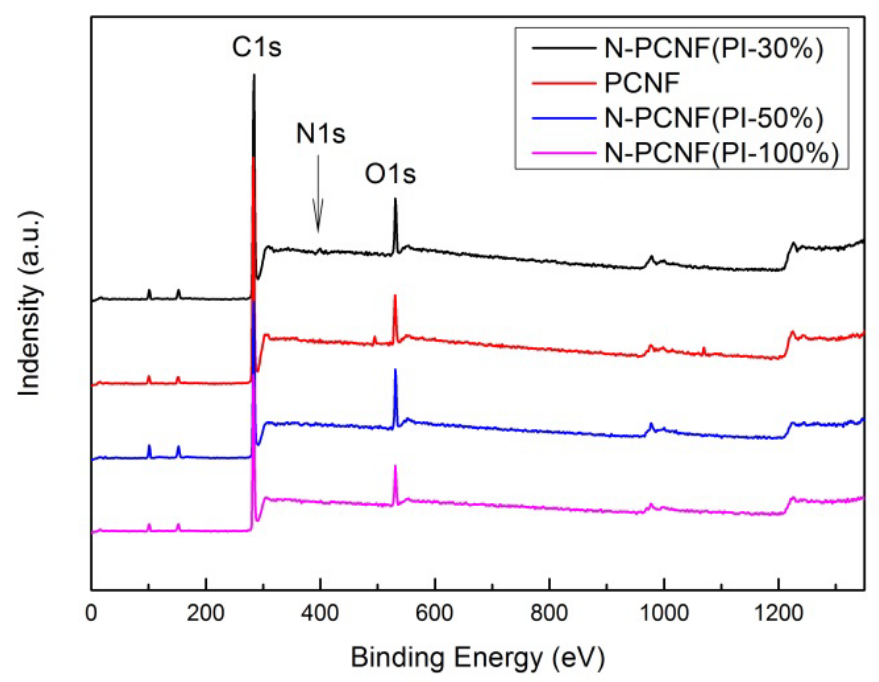

Figure 2. XPS survey spectra of PCNF, N-PCNF (PI-30\%), N-PCNF (PI-50\%) and N-PCNF (PI-100\%).

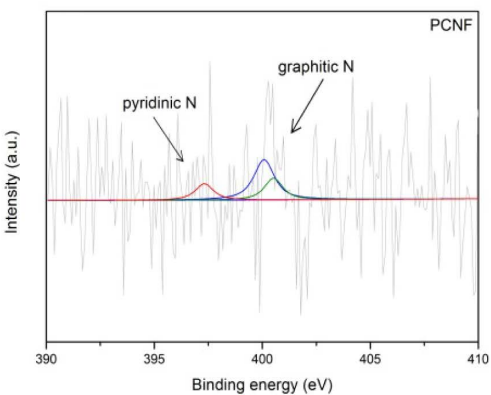

(a)

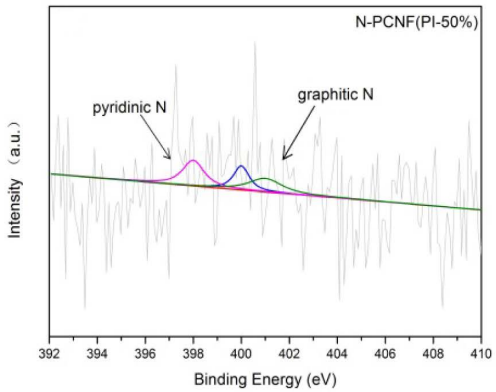

(c)

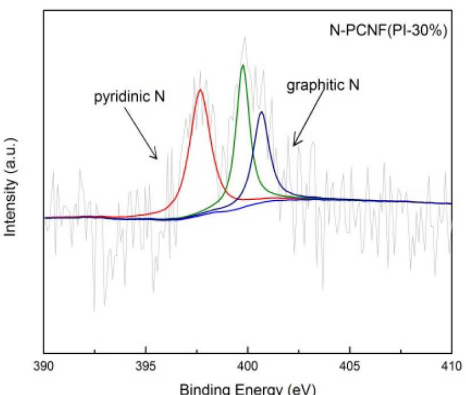

(b)

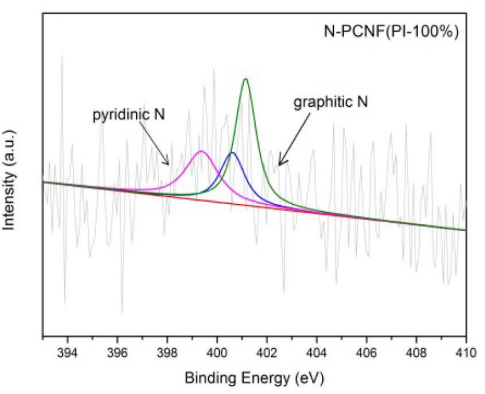

(d)

Figure 3. High resolution N1s XPS spectra of PCNF (a); N-PCNF (PI-30\%) (b); N-PCNF (PI-50\%) (c) and N-PCNF(PI-100\%) (d).

Table 1. Atomic content of samples from XPS spectra.

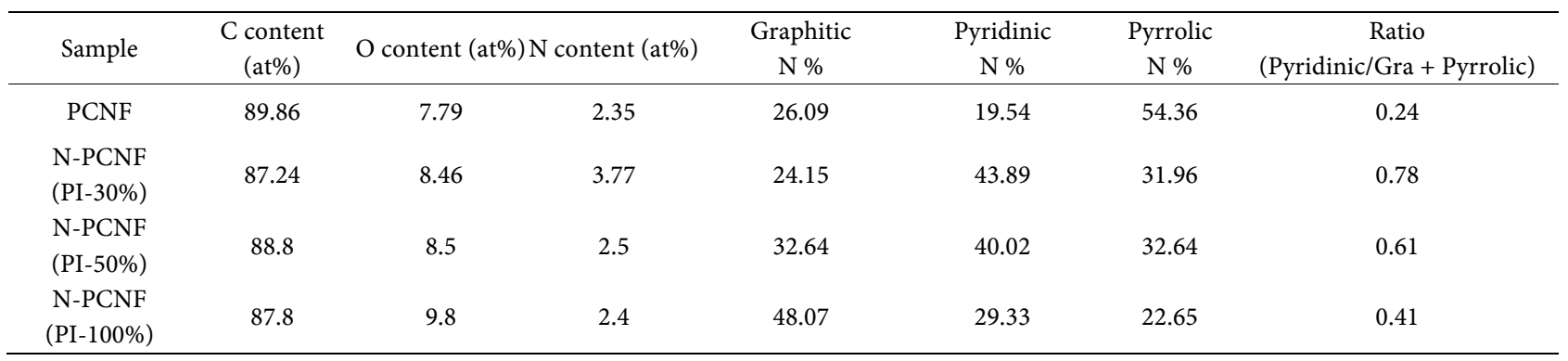



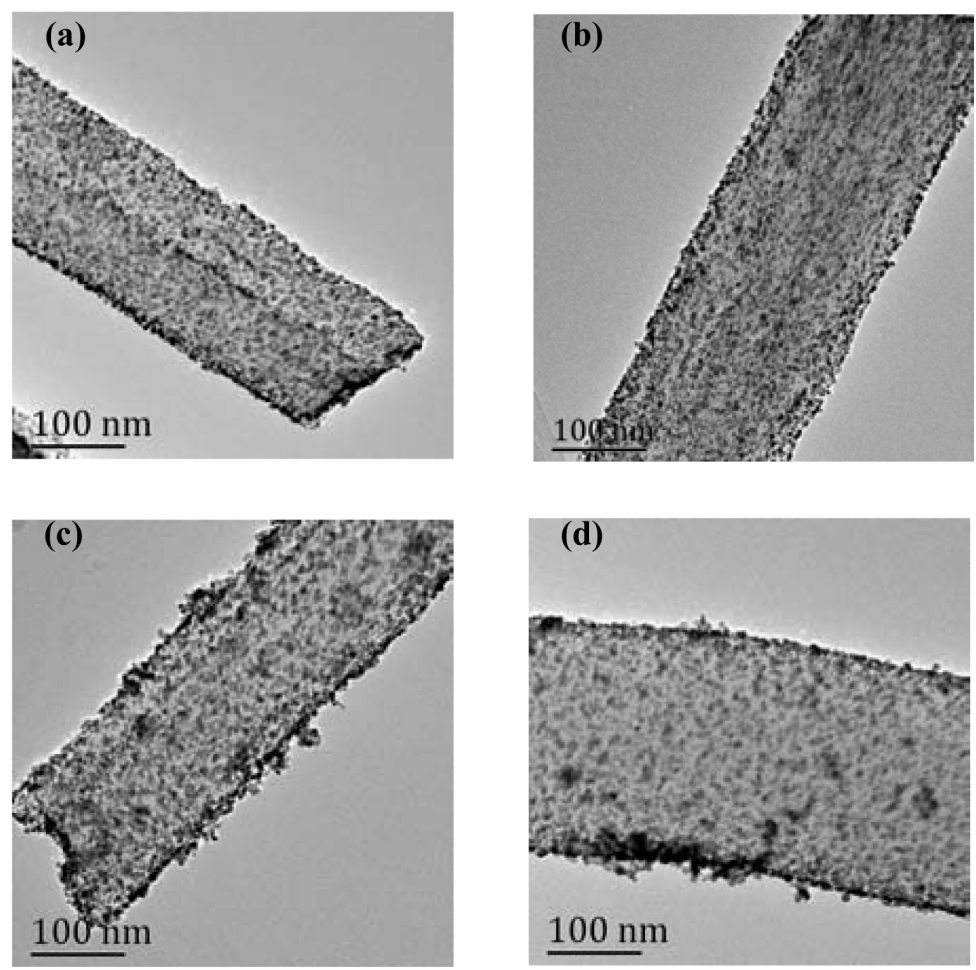

Figure 4. TEM images of PCNF (a); N-PCNF(PI-30\%) (b); N-PCNF(PI-50\%) (c) and N-PCNF(PI-100\%) (d).

showed smaller size distribution of Pt nanoparticles. In addition, the figure indicated that the nanoparticles tended to grow on the defects part or pores of the fibers. In this case, the N-PCNF (PI-30\%) showed the better condition of Pt nanoparticles which were expected to boost the catalytic activity.

To evaluate the catalytic activities of Pt/N-PCNFs for ORR, we tested normal $\mathrm{CV}$ patterns in $\mathrm{N}_{2}$-saturated $0.1 \mathrm{M} \mathrm{HClO}_{4}$ solution. Two distinct characteristic peaks can be seen in Figure 5(a). The peaks below 0.4V were related to hydrogen adsorption/desorption and the peaks in the range of $0.6 \mathrm{~V}-1.2 \mathrm{~V}$ were $\mathrm{Pt}$ oxidation/reduction. The electrochemical active surface (ECSA), representing the intrinsic activity of Pt catalysts, was calculated by the integration areas of hydrogen desorption area after removing the contribution of the capacitance [12] [13]. The value of ECSA for Pt/PCNF, Pt/N-PCNF (PI-30\%), Pt/N-PCNF (PI-50\%) and Pt/N-PCNF (PI-100\%) was 75.19, 67.67, 70.50, 31.63, $15.41 \mathrm{~m}^{2} \cdot \mathrm{g}^{-1}$, respectively (Table 2 ). Among four samples, $\mathrm{Pt} / \mathrm{N}-\mathrm{PCNF}$ (PI-30\%) displayed the most notable peak which may be attributed to the synergistic effect of high content of the nitrogen and pyridinic nitrogen which could provide more active sites [7].

LSV (b) curves of PCNF, N-PCNF (PI-30\%), N-PCNF (PI-50\%) and N-PCNF (PI-100\%) in $0.1 \mathrm{M} \mathrm{HClO}_{4}$ at ambient temperature with a potential scanning rate of $5 \mathrm{mV} / \mathrm{s}$ and $1600 \mathrm{rpm} \mathrm{RDE}$ rotation rate.

The rotating disk measurements (RDE) was also carried out in $\mathrm{O}_{2}$ saturated $0.1 \mathrm{M} \mathrm{HClO}_{4}$ solution to further evaluate electrochemical performance. As displayed in Figure 5(b), the curves indicated that the Pt/N-PCNF (PI-30\%) had 


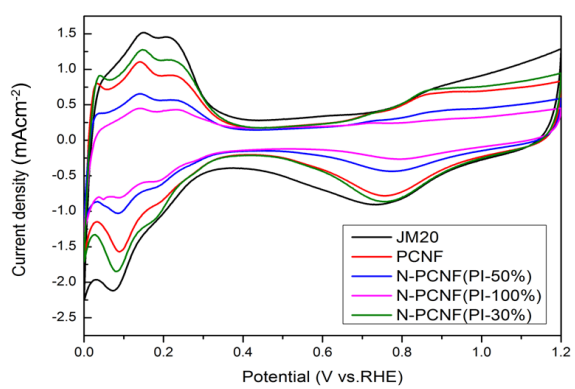

(a)

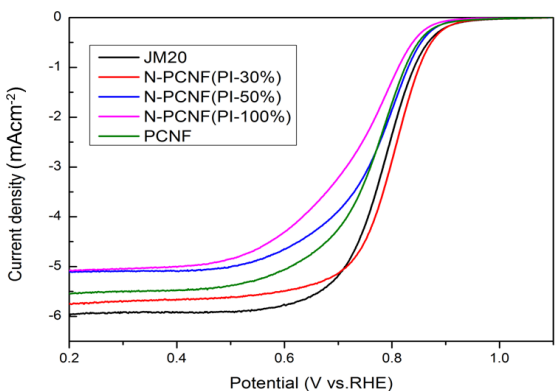

(b)

Figure 5. CV (a) curves of PCNF, N-PCNF (PI-30\%), N-PCNF (PI-50\%) and N-PCNF (PI- $100 \%)$ in $0.1 \mathrm{M} \mathrm{HClO}_{4}$ at ambient temperature with a potential scanning rate of 50 $\mathrm{mV} / \mathrm{s}$.

Table 2. Result of the CV and LSV measurement.

\begin{tabular}{cccc}
\hline Sample & $\begin{array}{c}\text { ECSA } \\
\left(\mathrm{m}^{2} \cdot \mathrm{g}^{-1}\right)\end{array}$ & $\begin{array}{c}\text { Onset potential } \\
(\mathrm{V})\end{array}$ & $\begin{array}{c}\triangle \mathrm{E} 1 / 2 \\
(\mathrm{~V})\end{array}$ \\
\hline JM20 & 75.19 & 0.923 & 0.785 \\
PCNF & 76.67 & 0.905 & 0.768 \\
PCNF- N-PCNF(PI-30\%) & 70.5 & 0.926 & 0.79 \\
N-PCNF(PI-50\%) & 31.63 & 0.902 & 0.77 \\
N-PCNF(PI-100\%) & 15.41 & 0.887 & 0.743 \\
\hline
\end{tabular}

remarkable ORR performance in terms of positive onset potential $(0.926 \mathrm{~V})$ and half-wave potentials $(0.790 \mathrm{~V})$. Catalytic activity of Pt/N-PCNF (PI-30\%) exceed those of other catalysts even JM20. The improved performance may be attributed to the integrative effect of nitrogen structure and microstructure which can significantly improve the accessibility of the active sites for reaction [14]. Although the limited currents density was lower than that of JM20 catalyst, it's increased a lot compared with other catalysts. The result suggested the specific characteristics of Pt/N-PCNF which could enhance the ORR activity.

\section{Conclusion}

The nitrogen-doped porous nanofibers were successfully fabricated by cost effective electrospinning technique and subsequent carbonization. Pt/N-PCNFs showed excellent ORR activity. The porous structure enabled the fibers with rough surface and defects. Furthermore the blending of PI increased the overall $\mathrm{N}$ content and pyridinic $\mathrm{N}$ which significantly boosted the exposure of active sites for ORR. That is to say, a preferential structure for catalyzing ORR process would be the outcome of the balance of content and types of nitrogen and defects. N-PCNF (PI-30\%) showed the better performance that can be employed as a promising oxygen reduction reaction electro-catalysts support.

\section{References}

[1] Grillo, G. and Debe, M.K. (2012) Electrocatalyst Approaches and Challenges for 
Automotive Fuel cells. Nature, 486, 43-51.

https://www.nature.com/nature/journal/v486/n7401/full/nature11115.html https://doi.org/10.1038/nature11115

[2] Wang, L., Ambrosi, A. and Pumera, M. (2013) "Metal-Free" Catalytic Oxygen Reduction Reaction on Heteroatom-Doped Graphene Is Caused by Trace Metal Impurities. Angewandte Chemie, 52, 13818-13821.

http://onlinelibrary.wiley.com/doi/10.1002/anie.201309171/abstract;jsessionid=801 F47A689

https://doi.org/10.1002/anie.201309171

[3] Zhou, X.J., Bai, Z.Y., Wu, M.J., Qiao, J.L. and Chen, Z.W. (2015) 3-Dimensional porous N-Doped Graphene Foam as a Non-Precious Catalyst for the Oxygen Reduction reaction. Journal of Materials Chemistry A, 3, 43-50. http://pubs.rsc.org/en/Content/ArticleLanding/2015/TA/C4TA06538G\#!divAbstrac $\underline{t}$

[4] Cui, X.Y., Yang, S.B., Yan, X.X., Leng, J.G., Shuang, S., Ajayan, P.M. and Zhang, Z.J. (2016) Pyridinic-Nitrogen-Dominated Graphene Aerogels with Fe-N-C Coordination for Highly Efficient Oxygen Reduction Reaction. Advanced Functional Materials, 26, 5708-5717.

http://onlinelibrary.wiley.com/doi/10.1002/adfm.201601492/abstract https://doi.org/10.1002/adfm.201601492

[5] Unni, S.M., Bhange, S.N., Illathvalappil, R., Mutneja, N., Patil, K.R. and Kurungot, S. (2015) Nitrogen-Induced Surface Area and Conductivity Modulation of Carbon Nanohorn and Its Function as an Efficient Metal-Free Oxygen Reduction Electrocatalyst for Anion-Exchange Membrane Fuel Cells. Small, 11, 352-360. http://onlinelibrary.wiley.com/doi/10.1002/smll.201303892/abstract https://doi.org/10.1002/smll.201303892

[6] Yang, D.S., Chaudhari, S., Rajesh, K.P. and Yu, J.S. (2014) Preparation of Nitrogen-Doped Porous Carbon Nanofibers and the Effect of Porosity, Electrical Conductivity, and Nitrogen Content on Their Oxygen Reduction Performance. Chemcatchem, 6, 36-44.

http://onlinelibrary.wiley.com/doi/10.1002/cctc.201400035/abstract

[7] Hassen, D., Shenashen, M.A., El-Safty, S.A., Selim, M.M., Isago, H., Elmarakbi, A., El-Safty, A. and Yamaguchi, H. (2016) Nitrogen-Doped Carbon-Embedded TiO2 Nanofibers as Promising Oxygen Reduction Reaction Electrocatalysts. Journal of Power Sources, 330, 292-303.

http://www.sciencedirect.com/science/article/pii/S0378775316311600 https://doi.org/10.1016/j.jpowsour.2016.08.140

[8] Qiu, Y.J., Yin, J., Hou, H.W., Yu, J. and Zuo, X.B. (2013) Preparation of Nitrogendoped Carbon Submicrotubes by Coaxial Electrospinning and Their Electrocatalytic Activity for Oxygen Reduction Reaction in Acid Media. Electrochimica Acta, 96, 5-9. http://www.sciencedirect.com/science/article/pii/S0013468613003423 https://doi.org/10.1016/j.electacta.2013.02.097

[9] Wang, Y., Jin, J.H., Yang, S.L., Li, G. and Qiao, J.L. (2015) Highly Active and Stable Platinum Catalyst Supported on Porous Carbon Nanofibers for Improved Performance of PEMFC. Electrochimica Acta, 177, 1-9.

http://www.sciencedirect.com/science/article/pii/S0013468615001802 https://doi.org/10.1016/j.electacta.2015.01.134

[10] Wu, J., Ma, L., Yadav, R.M., Yang, Y., Zhang, X., Vajtai, R., Lou, J. and Ajayan, P.M. (2015) Nitrogen-Doped Graphene with Pyridinic Dominance as a Highly Active and Stable Electrocatalysts for Oxygen Reduction. ACS Applied Materials \& Interfaces, 7, 14763-14769. 
http://pubs.acs.org/doi/abs/10.1021/acsami.5b02902 https://doi.org/10.1021/acsami.5b02902

[11] Wu, K.-H., Wang, D.-W., Su, D.S. and Gentle, I.R. (2015) A Discussion on the Activity Origin in Metal-Free Nitrogen-Doped Carbons for Oxygen Reduction Reaction and Their Mechanisms. ChemSusChem, 8, 2772-2788.

http://onlinelibrary.wiley.com/doi/10.1002/cssc.201500373/abstract https://doi.org/10.1002/cssc.201500373

[12] Hong, T.Z., Xue, Q., Yang, Z.Y. and Dong, Y.P. (2016) Great-Enhanced Performance of Pt Nanoparticles by the Unique Carbon Quantum Dot/Reduced Graphene Oxide Hybrid Supports towards Methanol Electrochemical Oxidation. Journal of Power Sources, 303, 109-117.

http://www.sciencedirect.com/science/article/pii/S0378775315304808 https://doi.org/10.1016/j.jpowsour.2015.10.092

[13] Song, J., Li, G. and Qiao, J.L. (2015) Ultrafine Porous Carbon Fiber and Its Supported Platinum Catalyst for Enhancing Performance of Proton Exchange Membrane Fuel Cells. Electrochimica Acta, 177, 174-180.

http://www.sciencedirect.com/science/article/pii/S0013468615007598

https://doi.org/10.1016/j.electacta.2015.03.142

Submit or recommend next manuscript to SCIRP and we will provide best service for you:

Accepting pre-submission inquiries through Email, Facebook, LinkedIn, Twitter, etc. A wide selection of journals (inclusive of 9 subjects, more than 200 journals) Providing 24-hour high-quality service User-friendly online submission system Fair and swift peer-review system Efficient typesetting and proofreading procedure Display of the result of downloads and visits, as well as the number of cited articles Maximum dissemination of your research work

Submit your manuscript at: http://papersubmission.scirp.org/ Or contact msce@scirp.org 